American Journal of BioScience
$2021 ; 9(4): 122-127$
http://www.sciencepublishinggroup.com/j/ajbio
doi: 10.11648 /j.ajbio.20210904.12
ISSN: 2330 -0159 (Print); ISSN: 2330 -0167 (Online)

\title{
Maize Germplasm Characterization Using Principal Component and Cluster Analysis
}

\author{
Solomon Mengistu \\ Harar Biodiversity Center, Ethiopian Biodiversity Institute, Addis Ababa, Ethiopia
}

Email address:

mengistusolomon7@gmail.com

\section{To cite this article:}

Solomon Mengistu. Maize Germplasm Characterization Using Principal Component and Cluster Analysis. American Journal of Bioscience and Bioengineering. Vol. 9, No. 4, 2021, pp. 122-127. doi: 10.11648/j.ajbio.20210904.12

Received: May 25, 2021; Accepted: July 5, 2021; Published: July 16, 2021

\begin{abstract}
In Ethiopian Biodiversity Institute Gene bank, large collections of maize germplasm are not yet characterized for the magnitude of genetic variability from each other. Although, knowing the contribution of individual a character is essential to focus on particular characters in cultivar development. Hence, this experiment was conducted on 92 maize accessions which were not yet characterized and 2 local checks to estimate the magnitude of genetic diversity among the genotypes and to identify the major agro-morphological characters contributing for the observed variations. The experiment was arranged in an Augmented Design in seven blocks at Arsi Negele in the 2016 main cropping season. The characters used for analysis were days to flowering, plant height, ear height, ear per plant, days to maturity, ear length, kernel rows per ear, a thousand grain weight and yield per plot. The 94 genotypes were grouped into four clusters where cluster I, II, III, and IV comprised 30, 21, 23, and 20 genotypes, respectively. Early matured and short genotypes were grouped in cluster IV, late matured in cluster II, and high yielding and tall genotypes in cluster I. The principal component analysis indicated that the first principal component (PC1) had an eigenvalue of 4.4 and reflects $48.85 \%$ of the total variation, this represents the equivalent of two individual variables and the two variables that weighted higher than the other variables are plant height and ear length. The second principal component (PC2) was a recorded eigenvalue of 1.63 and maintained $18.11 \%$ of the total variation and related to diversity among genotypes due to ear per plant (EPP). Moreover, principal components 3 to 9 were shown to have more than one eigenvalue, thus they represent equivalent of one individual variable each accounted for $0.98 \%, 0.78 \%, 0.68 \%, 0.35 \%, 0.15 \%, 0.03 \%$ and $0 \%$ respectively toward the variation observed among genotypes. The result ensures the existence of high genetic divergence among the studied maize genotypes.
\end{abstract}

Keywords: Maize, Germplasm, Quantitative Characters, Variability, Principal Component Analysis, Cluster Analysis

\section{Introduction}

Maize (Zea mays L.) is one of the popular crops grown in the world, ranking second to wheat and followed by rice [1]. It occupies an important position in the world economy as food, feed, and industrial grain crop. It is a staple food for several million people in the developing world where they derive their protein and calorie requirements from it. Maize is among the leading cereal crops selected to achieve food self-sufficiency in Ethiopia [2]. Although improved cultivars have been largely included in the national extension package, the national average yield of maize is only 3.45 tons/ha [3], which is far below the world average of 5.5 tons/ha. In any crop germplasm resource not only serves as a valuable source of useful genes but also provides a wide genetic variability. Bringing improvement over existing crop varieties is a continuous process in plant breeding. To achieve this objective, the breeder has to identify diverse parents having superior genetic variability for combining desirable characters. Therefore, knowledge of sound genetic diversity is essential for undertaking any recombination breeding program. Multivariate statistical techniques used to analyze multiple measurements on each individual and used in the analysis of genetic diversity. Among the multivariate techniques, principal component analysis (PCA) and cluster analysis have been shown to be very useful in selecting genotypes for breeding programs that meet the objective of a plant breeder [4]. PCA may be used to reveal patterns and eliminate redundancy in data sets [5], as morphological and physiological variations routinely occur in crop species. Cluster analysis is commonly used to study genetic diversity and for 
forming core subset for grouping accessions with similar characteristics into homogenous categories. Cluster analysis is frequently used to classify maize accessions and can be used by breeders and geneticists to identify subsets of accessions which have potential utility for specific breeding or genetic purposes [6]. Therefore, the objective of this study was aimed to estimate the magnitude of genetic diversity among the maize genotypes and to identify the major agro-morphological characters contributing for the observed variations.

\section{Materials and Methods}

The study was conducted during the year 2016 at the experimental field of Arsi Negele, Oromia Regional State, Ethiopia. It is located at $7^{\circ} 21^{\prime} \mathrm{N} 38^{\circ} 42^{\prime} \mathrm{E}$ and at an elevation of 1940 m.a.s.l. It has a chromic and pellic vertisol with $\mathrm{PH}$ values of 5-7. The annual rainfall of the location is measured $915 \mathrm{~mm}$ with $27 \pm 0.30^{\circ} \mathrm{C}$ mean daily temperature. 92 maize accessions obtained from Ethiopian Biodiversity Institute and two local checks named check 1 and 2 were grown at the farm site. Ninety two maize accessions without replication along with two replicated checks were arranged in an augmented design. Individual plot size measured $9 \mathrm{~m} \times 1.5 \mathrm{~m}$ with 4 rows planted at a spacing of $75 * 30 \mathrm{~cm}$. Recommended doses of fertilizers were applied. The other management operations were done timely and properly to raise the crop uniformly. Twenty randomly selected plants were used for recording observations on days to flowering, plant height, ear height, ear per plant, days to maturity, ear length and kernel rows per ear, a thousand grain weight, and yield per plot. The data collected for all quantitative characters were subjected to analysis of basic statistics, correlation, cluster and principal component analysis using the software Statistical Package for the Social Sciences (SPSS) 16.0 package [7].

\section{Results and Discussion}

In the present study, genetic diversity was analyzed among 94 maize genotypes (Table 6) on the basis of 9 agronomic and morphological characters. From the results of descriptive analysis (Table 1), ear height (EH) showed the highest variation $(35.52 \%)$ followed by the number of ears per plant $(30.39 \%)$. Conversely, the lowest variation was recorded for kernel rows per ear $(6.01 \%)$ and days to maturity $(9.61 \%)$.

Table 1. Basic statistics for various characters of maize genotypes.

\begin{tabular}{|c|c|c|c|c|c|c|}
\hline Characters & Mean & Minimum & Maximum & Range & SD & CV (\%) \\
\hline Days to flowering & 107.00 & 59.00 & 134.00 & 75.00 & 13.75 & 12.85 \\
\hline Plant height (m) & 2.23 & 1.10 & 3.04 & 1.94 & 0.41 & 18.36 \\
\hline Ear height (m) & 1.05 & 0.26 & 1.95 & 1.69 & 0.37 & 35.52 \\
\hline Ear per plant & 1.95 & 0.00 & 3.10 & 3.10 & 0.59 & 30.39 \\
\hline Days to maturity & 143.00 & 95.00 & 170.00 & 75.00 & 13.75 & 9.61 \\
\hline Ear length $(\mathrm{cm})$ & 15.13 & 10.70 & 19.00 & 8.30 & 1.80 & 11.90 \\
\hline Kernel rows per ear & 12.28 & 9.80 & 14.40 & 4.60 & 0.74 & 6.01 \\
\hline Yield (kg/plot) & 5.78 & 3.37 & 7.69 & 4.32 & 0.95 & 16.45 \\
\hline
\end{tabular}

$\mathrm{SD}=$ Standard deviation, $\mathrm{CV}=$ Coefficient of variation

Simple correlation coefficients confirmed that yield per plot recorded highly significant positive correlations among plant height, ear length, and thousand grain weight, and maintained positive significant correlation among days to flower, ear height, days to maturity, and kernel rows per ear. Likewise, ear per plant was recorded insignificant negative correlations with days to flowering, plant height, and ear height (Table 2). Similarly, Aliu [8] found a highly significant positive correlation of grain yield with cob diameter and thousand kernels weight and a significant positive correlation with plant height.

Table 2. Phenotypic correlation coefficients for different traits on maize genotypes.

\begin{tabular}{|c|c|c|c|c|c|c|c|c|c|}
\hline & DF & PH & EH & EPP & DM & EL & KRPE & TGW & YPP \\
\hline $\mathrm{DF}$ & 1.00 & $0.59218 * *$ & $0.59323 * *$ & -0.092 & $1.00000 * *$ & $0.43338 * *$ & 0.18989 & $0.22982 *$ & $0.25984 *$ \\
\hline PH & & 1.00 & $0.96212 * *$ & -0.009 & $0.59218 * *$ & $0.68246 * *$ & $0.37618^{*}$ & $0.47818 * *$ & $0.41423 * *$ \\
\hline $\mathrm{EH}$ & & & 1.00 & -0.018 & $0.59323 * *$ & $0.62418 * *$ & $0.31869^{*}$ & $0.41280 * *$ & $0.37949^{*}$ \\
\hline EPP & & & & 1.00 & -0.09127 & $0.23183^{*}$ & 0.13729 & 0.17099 & 0.0399 \\
\hline DM & & & & & 1.00 & $0.43338 * *$ & 0.18989 & $0.22982 *$ & $0.25984 *$ \\
\hline EL & & & & & & 1.00 & $0.42315^{* *}$ & $0.57258 * *$ & $0.45637 * *$ \\
\hline KRPE & & & & & & & 1.00 & 0.36272 & $0.31602 *$ \\
\hline YPP & & & & & & & & & 1.00 \\
\hline
\end{tabular}

*Significant at $\mathrm{P}=0.05$, ** Significant at $\mathrm{P}=0.01, \mathrm{DF}=$ Days to flowering, $\mathrm{PH}=\mathrm{Plant}$ height, $\mathrm{EH}=\mathrm{Ear}$ height, $\mathrm{EPP}=\mathrm{Ear}$ per plant, $\mathrm{DM}=\mathrm{Days}$ to $\mathrm{mat}$ rity, $\mathrm{EL}=$ Ear length, $\mathrm{KRPE}=$ Kernel rows per ear, $\mathrm{TGW}=$ Thousand grain weight, and $\mathrm{YPP}=$ Yield per plot

\subsection{Principal Component Analysis}

The nine components which had an eigenvalue equal to or greater than one were retained as meaningful interpretations (Table 3). The principal component analysis indicated that the first principal component (PC1) had an eigenvalue of 4.4 and reflects $48.85 \%$ of the total variation (Table 3 ), this represents 
the equivalent of two individual variables and the two variables that weighted higher than the other variables are plant height $(\mathrm{PH})$ and ear height $(\mathrm{EH})$. The second principal component (PC2) recorded an eigenvalue of 1.63 and maintained $18.11 \%$ of the total variation. PC2 also represents the equivalent of two variables which are a thousand grain weight and yield per plot. Moreover, principal components 3 to 9 were shown to have more than one eigenvalue, thus they represent equivalent of one individual variable each accounted for $0.98 \%, 0.78 \%, 0.68 \%, 0.35 \%, 0.15 \%, 0.03 \%$, and $0 \%$ respectively towards the total variation.

Table 3. Principle component analysis of different characters on maize genotypes.

\begin{tabular}{|c|c|c|c|c|c|c|c|c|c|}
\hline Eigenvalue & 4.40 & 1.63 & 0.98 & 0.78 & 0.68 & 0.35 & 0.15 & 0.03 & 0.00 \\
\hline$\%$ of total variance & 48.85 & 18.14 & 10.93 & 8.63 & 7.59 & 3.85 & 1.66 & 0.35 & 0.00 \\
\hline Cumulative variance $\%$ & 48.85 & 66.99 & 77.92 & 86.55 & 94.14 & 97.99 & 99.65 & 100 & 100 \\
\hline
\end{tabular}

Table 4. The principal component of traits used for cluster analysis.

\begin{tabular}{|c|c|c|c|c|c|c|c|c|c|}
\hline Character & PC1 & PC2 & PC3 & PC4 & PC5 & PC6 & PC7 & PC8 & PC9 \\
\hline $\mathrm{DF}$ & 0.36 & -0.43 & 0.07 & 0.29 & 0.30 & 0.00 & -0.04 & 0.00 & 0.71 \\
\hline PH & 0.43 & -0.09 & 0.06 & -0.27 & -0.38 & 0.22 & -0.06 & -0.73 & 0.00 \\
\hline EH & 0.41 & -0.13 & 0.07 & -0.25 & -0.43 & 0.33 & 0.07 & 0.67 & 0.00 \\
\hline EPP & 0.03 & 0.40 & 0.76 & 0.42 & -0.03 & 0.28 & 0.06 & -0.02 & 0.00 \\
\hline DM & 0.36 & -0.43 & 0.07 & 0.29 & 0.30 & 0.00 & -0.04 & 0.00 & -0.71 \\
\hline EL & 0.38 & 0.18 & 0.21 & -0.05 & -0.17 & -0.85 & 0.17 & 0.05 & 0.00 \\
\hline KRPE & 0.24 & 0.27 & 0.18 & -0.62 & 0.66 & 0.11 & 0.00 & 0.03 & 0.00 \\
\hline YPP & 0.30 & 0.38 & -0.48 & 0.27 & 0.10 & 0.18 & 0.65 & -0.06 & 0.00 \\
\hline
\end{tabular}

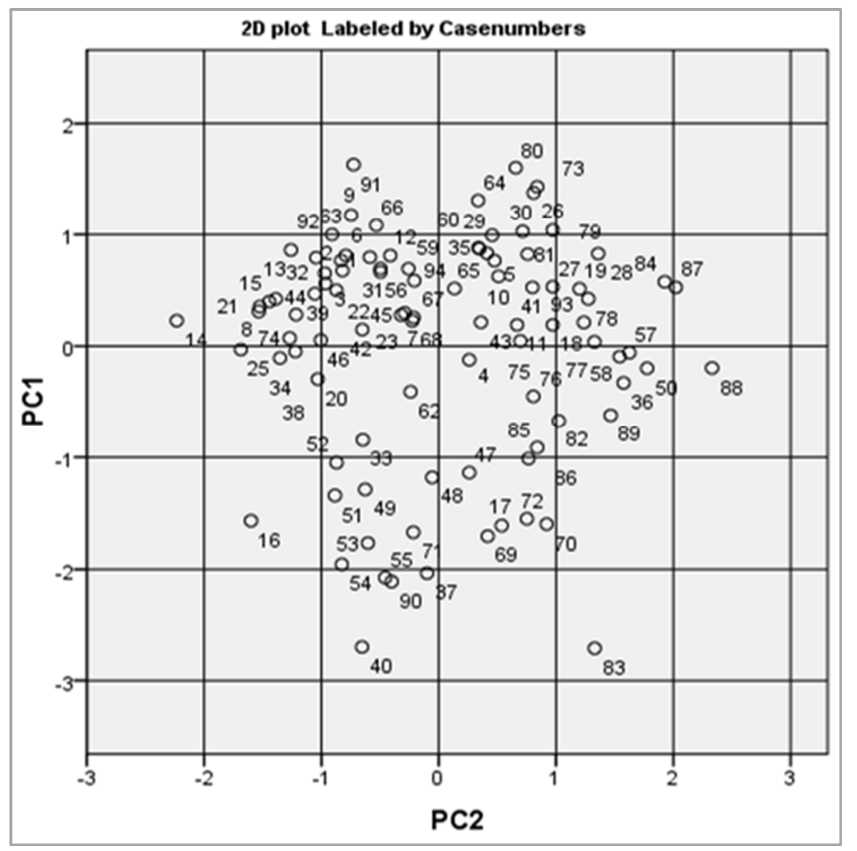

Figure 1. Distribution of maize accessions for the first two principal components.

The PC3 showed high weight in ear per plant (EPP) and probably reflects yield. The fifth principal component (PC5) kernel rows per ear (KRPE) had the largest weight, thus reflecting yield. The seventh principal component (PC7) showed a high value on yield per plot (YPP). Eighth principal component (PC8) had accounted high value of ear height $(\mathrm{EH})$, this probably reflects the plant structure. Moreover, the ninth principal component (PC9) recorded the highest value on days to flowering (DF), thus reflecting flower development. In this study the principal component analysis categorized the total variance into nine (9) principal components and contributed maximum towards the total diversity. Similarly, [9, 10] reported the important contribution of the first PCs in the total variability while studying various traits. Principal component analysis (PCA) is usually used in plant sciences for the reduction of variables and grouping of genotypes. Several authors suggested first principal component (PC) scores as input variables for the clustering process [9].

\subsection{Cluster Analysis}

Clustering pattern of maize accessions under this experiment reveals that the maize germplasm showed considerable genetic diversity among them by occupying four different clusters (Table 5). These maizes germplasm were grouped based mainly on day to flowering, plant height, ear height, ear per plant, days to maturity, ear length, kernel rows per ear, a thousand grain weights and yield as variables. Ninety four maize genotypes were grouped into 4 clusters based on various agro-morphological characters. Cluster I to IV were comprised 30,21, 23, and 20 maize genotypes respectively (Table 6). Thus, Cluster I (Table 5) was maintained maximum plant height $(2.42 \mathrm{~m})$, ear height $(1.21$ $\mathrm{m})$, ear per plant $(2.25)$, ear length $(16.21 \mathrm{~cm})$, kernel rows per ear (12.61) and yield (6.58 kg/plot). Cluster II showed late days to flowering (120.9 days) and maturing nature (156.9 days). Cluster III also maintained higher yield (5.88 kg/plot). Moreover cluster IV was showed relatively early maturing character (133.5 days) but had minimum values of plant height $(1.84 \mathrm{~m})$, ear height $(0.74 \mathrm{~m})$, ear length $(13.34 \mathrm{~cm})$, kernel row per ear (11.82), and low yield (4.5 kg/plot). Similarly, hierarchical cluster analysis has been suggested for classifying entries of germplasm collections based on degree of similarity and dissimilarity [11]. A combination of cluster and principal component analysis has been used to classify maize (Zea mays L.) accessions [12]. 


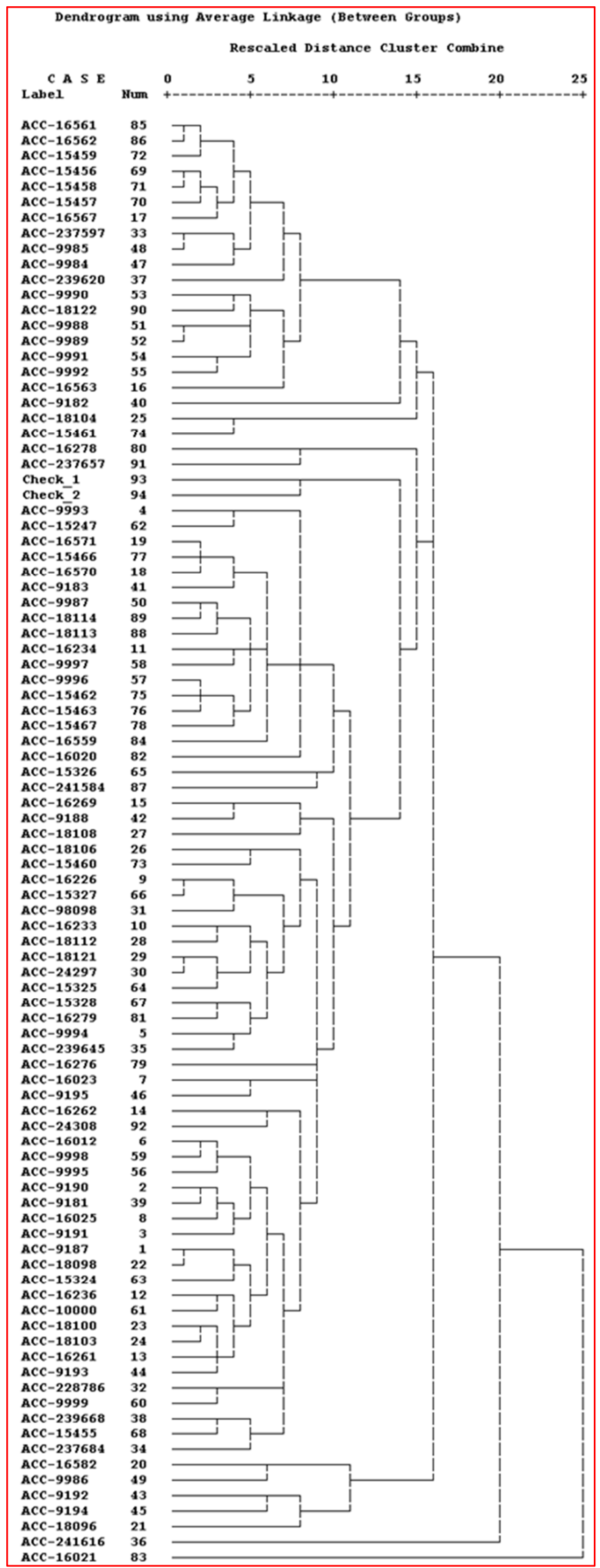

Figure 2. Dendrogram classifying the 94 genotypes based on agro-morphological characters. 
Table 5. Cluster means values for different agro- morphological characters of 94 genotypes.

\begin{tabular}{|c|c|c|c|c|}
\hline \multirow{2}{*}{ Character } & \multicolumn{4}{|c|}{ Cluster name } \\
\hline & $\mathbf{I}$ & II & III & IV \\
\hline $\mathrm{DF}$ & 109.2 & 120.9 & 99.7 & 97.5 \\
\hline PH & 2.42 & 2.4 & 2.17 & 1.84 \\
\hline $\mathrm{EH}$ & 1.21 & 1.2 & 0.97 & 0.74 \\
\hline EPP & 2.25 & 1.75 & 1.71 & 2 \\
\hline $\mathrm{DM}$ & 145.2 & 156.9 & 135.7 & 133.5 \\
\hline EL & 16.21 & 15.56 & 14.9 & 13.34 \\
\hline KRPE & 12.61 & 12.3 & 12.25 & 11.82 \\
\hline TGW & 396.93 & 330.19 & 338.09 & 259.45 \\
\hline YPP & 6.58 & 5.74 & 5.88 & 4.5 \\
\hline
\end{tabular}

Table 6. Clustering pattern of the 94 accessions based on agro-morphological characters.

\begin{tabular}{|c|c|c|c|c|c|c|c|}
\hline \multirow[t]{2}{*}{ Cluster name } & \multirow[t]{2}{*}{ No. of genotypes } & \multicolumn{6}{|c|}{ Name of accessions in each cluster } \\
\hline & & ACC-9994 & ACC-16226 & ACC-16233 & ACC- 16570 & ACC-16571 & ACC-18106 \\
\hline \multirow{4}{*}{ I } & \multirow{4}{*}{30} & ACC-18108 & ACC-18112 & ACC-18121 & ACC-24297 & ACC-9183 & ACC-9987 \\
\hline & & ACC-9995 & ACC-9996 & ACC-9998 & ACC-9999 & ACC-15325 & ACC-15326 \\
\hline & & ACC- 15460 & ACC-15466 & ACC-15467 & ACC-16276 & ACC-16278 & ACC-16279 \\
\hline & & ACC-16559 & ACC-241584 & ACC-18113 & ACC-237657 & Check_1 & Check_2 \\
\hline \multirow{4}{*}{ II } & \multirow{4}{*}{21} & ACC-9187 & ACC-9190 & ACC-9191 & ACC-16012 & ACC-16025 & ACC-16236 \\
\hline & & ACC-16261 & ACC-16269 & ACC-18096 & ACC-18098 & ACC- 18100 & ACC-18103 \\
\hline & & ACC-228786 & ACC-237684 & ACC-239668 & ACC-9181 & ACC- 10000 & ACC-15324 \\
\hline & & ACC-15327 & ACC-15455 & ACC- 24308 & & & \\
\hline \multirow{4}{*}{ III } & \multirow{4}{*}{23} & ACC-9993 & ACC-16023 & ACC-16234 & ACC-16582 & ACC-98098 & ACC-237597 \\
\hline & & ACC-239645 & ACC-241616 & ACC-9188 & ACC-9192 & ACC-9194 & ACC-9984 \\
\hline & & ACC-9985 & ACC-9986 & ACC-9997 & ACC-15247 & ACC-15328 & ACC-15462 \\
\hline & & ACC- 15463 & ACC- 16020 & ACC-16561 & ACC-16562 & ACC-18114 & \\
\hline \multirow{4}{*}{ IV } & \multirow{4}{*}{20} & ACC- 16262 & ACC- 16563 & ACC-16567 & ACC-18104 & ACC- 239620 & ACC-9182 \\
\hline & & ACC-9193 & ACC-9195 & ACC-9988 & ACC-9989 & ACC-9990 & ACC-9991 \\
\hline & & ACC-9992 & ACC-15456 & ACC-15457 & ACC-15458 & ACC-15459 & ACC-15461 \\
\hline & & ACC-16021 & ACC-18122 & & & & \\
\hline
\end{tabular}

The tree diagram comprises 4 main cluster groups and each of them further subdivided into sub clusters (Figure 2). The information regarding association among various traits is an important part for the initiation of any breeding program and gives a good chance for the selection of superior genotypes having desirable traits simultaneously [13].

\section{Conclusion}

Different methods are available to assess genetic variability among and within crop species. In the present study, principal component and cluster analysis techniques were employed to examine the amount of genetic variability present in a set of 94 maize genotypes. Thus, it can be inferred from the present investigation that high level of genetic variability was present in agronomic and morphological traits like days to flowering, plant height, ear height, ear per plant, days to maturity, ear length, kernel rows per ear, a thousand grain weight and yield per plot in the tested germplasm. Therefore, promising maize genotypes with more genetic divergence were identified. The identification of high levels of genetic variability during the current study could be indicated for germplasm characterization, conservation and further improvement in the maize breeding program.

\section{References}

[1] Vasal SK (2000) Quality maize story. In: Improving Human Nutrition through Agriculture. The Roll of International Agricultural Research. A workshop hosted by IRRI, Philippines, Organized by International Food Policy Institute, Los Banos, USA.

[2] Bello OB, Abdul Malik SY, Afolabi MS, Lge SA (2010) Correlation and path coefficient hybrids analysis of yield and agronomic characters among open pollinated maize varieties and their F1 in a diallel cross. AfrJBiotech 9 (18): 2633-2639.

[3] Central Statistical Authority (2015) Agriculture sample survey report on area and production for major crops for 2014/015. The FDRE Statistical Bulletin, CSA, Addis Ababa, Ethiopia.

[4] Mohammadi SA, Prasanna BM (2003). Analysis of genetic diversity in crop plants-salient statistical tools and considerations. Crop Sci. 43: 1235-1248.

[5] Adams MW (1995). An estimate of homogeneity in crop plants with special reference to genetic vulnerability in dry season. Phaseolus vulgaris. Euphytica, 26: 665-679.

[6] Rincon, F., Johnson, B., Crossa, J., \& Taba, S. (1996). Cluster analysis. An approach to sampling variability in maize [Zea mays L.] accessions. Maydica (Italy). 
[7] Levesque, R. (2007). SPSS. Statistical package for the social sciences, version 16.0. SPSS Programming and data management. A guide for SPSS and SAS users, fourth edition, SPSS inc., Chicago III.

[8] Aliu, S., I. Rusinvoci, S. Fetahu and K. Bislimi. (2013). Morpho-physiological Traits and Mineral Composition on Local Maize Population Growing in Agro Ecological Conditions in Kosovo. Notulae Scientia Biol., 5 (2): 232-237.

[9] Mujaju, C., Chakuya, E. (2008): Morphological variation of sorghum landrace accessions on-farm in Semi-arid areas of Zimbabwe. International Journal of Botany 4: 376-382.

[10] Ali., M. A., Jabran, K., Awan, S. I., Abbas, A., Ehsanullah, Zulkifal, M., Acet, T., Farooq, J., Rehman, A. (2011): Morpho-physiological diversity and its implications for improving drought tolerance in grain sorghum at different growth stages. Australian Journal of Crop Science 5 (3): 311-320.
[11] Van Hintum, T. J. L. (1995): Hierarchical approaches to the analysis of genetic diversity in crop plants. In: Hodgkin, T., Brown, A. H. D., Van Hintum T. J. L., Morales, E. A. V. (Eds.) Core collection of plant genetic resources. John Wiley and Sons, pp. 23-34.

[12] Crossa, J., Delacy, I. H., Taba, S. (1995): The use of multivariate methods in developing a core collection. p. 77-92. In: Hodgkin, T., Brown, A. H. D., Van Hintum, Th. J. L., Morales, E. A. V. (Eds.) Core collections of plant genetic resources. John Wiley \& Sons, Chichester, UK.

[13] Ali, M. A., Nawab, N. N., Abbas, A., Zulkiffal, M., Sajjad, M. (2009): Evaluation of selection criteria in Cicerarietinum L. Using correlation coefficients and path analysis. Australian Journal of Crop Science 3: 65-70. 